\title{
Use of infographics to communicate landmark glaucoma trials
}

\author{
Christin Henein $\mathbb{D}^{1} \cdot$ Rashmi G Mathew ${ }^{1,2}$
}

Received: 7 October 2020 / Revised: 6 December 2020 / Accepted: 9 December 2020 / Published online: 19 January 2021

(c) The Author(s), under exclusive licence to The Royal College of Ophthalmologists 2021

\section{Infographics in clinical research communication}

The power of infographics in communicating clinical research more effectively than words alone is becoming more widely acknowledged [1]. Infographics have a pertinent utility in succinctly conveying a lot information. In the context of an overwhelming growing body of medical research and progress in big data, clear messaging is paramount [2]. They have been particularly useful in conveying rapid messaging during the COVID pandemic across the NHS and communicating clinical research. A two-phase within-subject experiment found that participants preferred infographic research summaries to the traditional text-only research abstracts and found that infographics required lower cognitive load and did not worsen subjects' retention of information [3]. The study proposed infographics as an alternative representation of research findings or to accompany traditional text-only abstracts.

A crossover study showed that infographic abstracts were more effective than the title alone in generating research interest, which was measured as the amount of social-media interactions, article downloads, and reads [4]. A growing number of leading journals are leveraging the benefits of infographics in generating researcher and public engagement in clinical research and increasing the accessibility and appeal from a wider and nonspecialist readership [5]. Conversely, a failure to communicate clinical research clearly results in a gap between the research and its translation into clinical practice.

Rashmi G Mathew

r.mathew@ucl.ac.uk

UCL Institute of Ophthalmology, London, UK

2 Consultant Ophthalmologist, Moorfields Eye Hospital NHSFT, London, UK

\section{Use of infographics to enable clinicians to incorporate evidence into clinical care}

In order to provide patients with evidence-based medicine, ophthalmic clinicians are required to stay up to date with relevant ophthalmic literature. However, there are many factors that impact the incorporation of evidence into ophthalmic care, such as time constraints [6]. It takes skill and planning to make infographics intuitive and engaging for busy clinicians. In terms of layout, content, and formatting, infographics need to be accurate representations of the original article and highlight the key messages. Graph interpretation, numeracy skills, and domain knowledge are factors that could limit the wider reach of clinical research infographics and modifications are required to tailor information to suit the target audience.

\section{Use of infographics in ophthalmic education}

Some students are predominantly visual, verbal, or kinesthetic learners or a combination of the three. Infographics make use of multiple cognitive learning modalities. Allan Paivio's Coding Theory describes how people learn best when information is presented in multi-modalities [7], thus enabling the mind to encode information in both modes as well as to build referential links between the two representations. According to the Coding Theory, creating and presenting infographics have profound implications for students to maximize their learning [8, 9]. As a way of developing science communication, visual literacy and critical appraisal skills, pairs of students were asked to create an infographic for a designated landmark study in glaucoma [10] using a modified Cochrane dissemination checklist [11] (Fig. 1). In this and future editions of EYE, we present the infographics produced by UCL MSc in Ophthalmology students. 


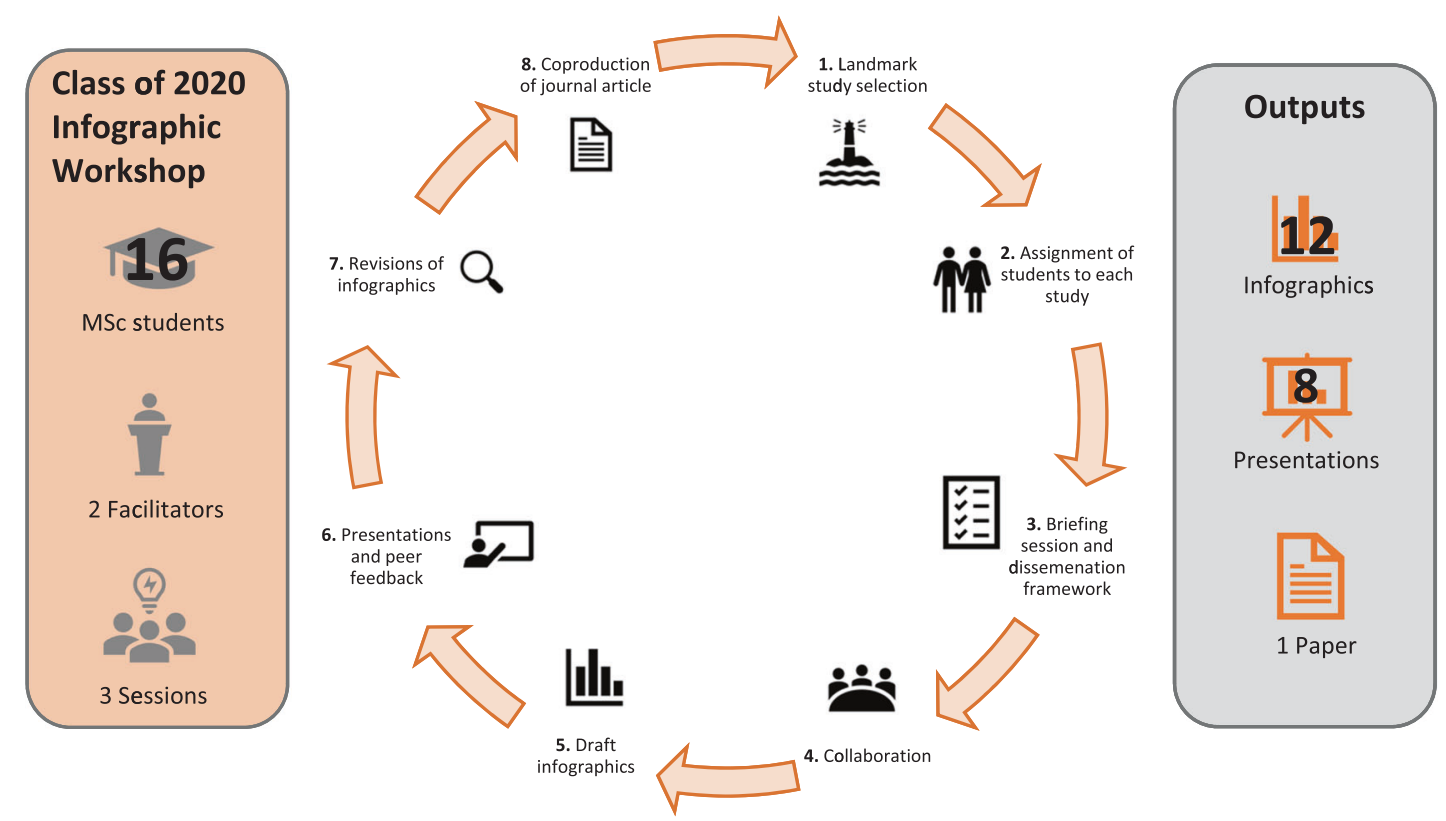

Fig. 1 Summary diagram outlining the 8 steps of the infographics workshop. The workshop was designed using the UCL Connected Curriculum, which is underpinned by student learning through research and enquiry. Step 1: Landmark glaucoma trials were identified from the UCL MSc Core Curriculum. Step 2: Preassigned pairs of students were allocated a landmark study and asked to produce an infographic and presentation. Step 3: As part of the briefing session for the workshop, students were provided with a modified dissemination checklist produced by Cochrane to follow when developing the infographic. The briefing session drew upon prior learning on shared decision making and risk communication. Step 4: Time was set aside to enable diverse groups of students to particpate in collaborative enquiry. Step 5: Students prepared short presentations of the key messages from their infographic to practice verbal science communication. Step 6 and 7: In a larger group setting facilitated by module leads; students peer-reviewed each pair's infographic to make iterative refinements to improve clarity and learn how to provide constructive feedback. Discussions also included how the research findings influenced clinical practice and clinical decision making. Step 8: Further quality assurances were made by module leads for the purposes of journal publication.

\section{Compliance with ethical standards}

Conflict of interest Rashmi Mathew is the glaucoma module lead for UCL MSc in Ophthalmology and Programme Co-Director for MSc in Advanced Clinical Practice in Ophthalmology and Advanced Clinical Optomtery and Ophthalmology and Christin Henein is the deputy glaucoma module lead for UCL MSc in Ophthalmology.

Publisher's note Springer Nature remains neutral with regard to jurisdictional claims in published maps and institutional affiliations.

\section{References}

1. Zikmund-Fisher BJ, Ubel PA, Smith DM, Derry HA, McClure JB, Stark A, et al. Communicating side effect risks in a tamoxifen prophylaxis decision aid: the debiasing influence of pictographs. Patient Educ Couns. 2008;73:209-14.

2. Bornmann L, Mutz R. Growth rates of modern science: a bibliometric analysis based on the number of publications and cited references. J Assoc Inf Sci Technol. 2015;66:2215-22.

3. Martin LJTA, Groot B, Huang SYM, Kok E, Thoma B, van Merriënboer JJG. Exploring the role of infographics for summarizing medical literature. Health Prof Educ. 2019;5:48-57.
4. Ibrahim AM, Lillemoe KD, Klingensmith ME, Dimick JB. Visual abstracts to disseminate research on social media: a prospective, case-control crossover study. Ann Surg. 2017;266:e46-8.

5. The Economist. Graphic details; A scientific study of the importance of diagrams to science. The Economist. Jun 18th 2016 ed; 2016.

6. Hong B, O'Sullivan ED, Henein C, Jones CM. Motivators and barriers to engagement with evidence-based practice among medical and dental trainees from the UK and Republic of Ireland: a national survey. BMJ Open. 2019;9:e031809.

7. Clark J, Paivio A. Dual coding theory and education. Educ Psychol Rev. 1991;3:149-210.

8. Moreno R, Mayer RE, Spires HA, Lester JC. The case for social agency in computer-based teaching: do students learn more deeply when they interact with animated pedagogical agents? Cogn Instr. 2001;19:177-213.

9. Mayer RE, Moreno R. Nine ways to reduce cognitive load in multimedia learning. Educ Psychol. 2003;38:43-52.

10. Wormald R, Virgili G, Azuara-Blanco A. Systematic reviews and randomised controlled trials on open angle glaucoma. Eye. 2020;34:161-7.

11. Glenton CRS, Fønhus MS. Checklist and guidance: for disseminating findings from Cochrane intervention reviews. Cochrane. https://training.cochrane.org/sites/training.cochrane.org/ files/public/uploads/Checklist\%20FINAL\%20version\%201.0.pdf. Accessed 3 Jun 2020. 